\title{
Embracing nature and culture: the tropical Malay spa design
}

\author{
A. Bahauddin \& A. Abdullah \\ School of Housing, Building \& Planning, \\ Universiti Sains Malaysia, Malaysia
}

\begin{abstract}
The tropical Malay spa design associated with a traditional Malay Single's House (Rumah Bujang) reveals a design construction in a setting that exploits the surroundings. It is strongly linked to the Malay heritage and cultural values. This paper explores the tropical design found in the Malay spa and how the spa activities are interrelated with the architecture that houses them. The Malay spa activities are glorified by the Malay people for the values of mysticism, spiritual enhancement, physical well being and emotional uplift and this architecture ensures the perpetuity of these cultural elements. This research ventures further into the design of the Malay spa, which can now only be found in small villages in the northern region of Malaysia and the east coast of Peninsular Malaysia. The methodology employed for this research records the visual data collection, architectural drawing documentation of spa design and observation of the activities that take place. Interviews with the owners of spas and the people receiving treatment provide a primary source of information. The Malay spa design depicts a humble vernacular architecture that nestles in a setting planted with fruit trees, flowers, herbs and spices. The Malay spa design in a Single's House can be studied as one example of sustainable tropical design. Proper planning of this architecture and its activity must be explored by complying with the traditional Malay philosophy, rituals and customs. The traditional values of the Malay people are apparent in this Malay spa, which justifies its continuation and has long been viewed as embracing nature in every sense of existence. The architectural elements portrayed are made strong with the symbiotic relationships between cultural elements and the natural surroundings.
\end{abstract}

Keywords: spiritual, rituals, natural setting, Malay spa, vernacular architecture, single's house. 


\section{Introduction}

This paper explores the Malay spa design associated with a traditional Malay house called a Single's House (Rumah Bujang), which re-emerged after the traditional Malay spa practices became publicly known in Malaysia (figure 1). The aspect of this tropical spa design clearly illustrates that the space planning and the environments are governed by the spa treatment activities. Current information available on house design only points out the basic data, which neglects the cultural and social aspects in detail. This is regarding the cultural influences particularly of the Malay culture, the philosophy and the 'whys' of the design, which were created along with the environment, within the perimeters of which this tropical Malay architecture style was erected [1].

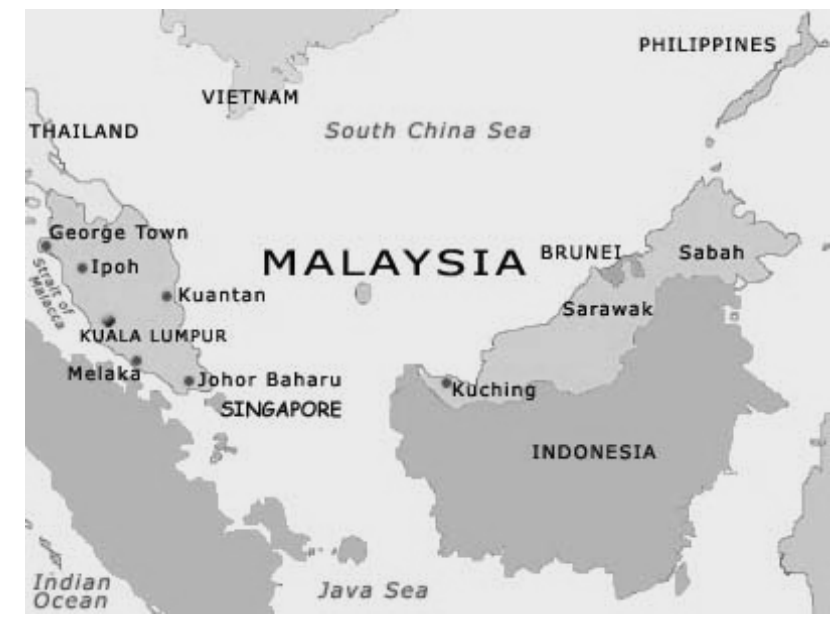

Figure 1: $\quad$ Map of Malaysia.

Every space designed for the spa in this house carries its own meaning and the space planning involved speaks of a deeper cultural background. The rituals, customs and traditions that are associated with the Malay spa design present a new understanding and meaning to the interior space planning and the display of the detail embellishments. The detail embellishments relate to decorations such as a carving, air vent, interior finishes and many more detailed embellishments to the house. The 'slow death' that this style of architecture is facing has so far been ignored and overlooked in the name of development. Malaysia has developed rapidly since the economic boom in the 1980s until now. The rapid development witnesses the urge to move from the traditional style of architecture into buildings constructed with modern materials as demand for quick and cheap houses rises. It is a move from the local traditional materials, such as timber for the main structure, bamboo strips for the walls and floors, and sago palm or nipah palm leaves for the walls and roofs. The change appears in the application of materials, such as using bricks and concrete for the walls and clay tile for roofs. The modern houses are always built directly on the ground as opposed to 
the traditional house, which is always built on stilts. This is to encourage interaction with the environment while providing ventilation, protection against wild animals and avoiding flood water during the rainy season.

The current house construction also neglects the basic requirements for comfort in the warm climate as found in the traditional house design. The most apparent problem with modern house design is in the sun orientation of the building. It faces a major problem, especially during the hottest time of the day, as the sun radiation heats up the house. Unlike the modern building, the traditional Malay house orientation always points to the south-east direction, where the sun's radiation is welcomed in the morning and avoided in the afternoon. Many people do not understand the importance of the Malay spa design in terms of its design and knowledge that it imparts in its association with sustainable design, the current hot and debated issue. The Malay spa design has a lot to offer regarding the application of nature related elements, such as natural ventilation and natural lighting, which lower dependency on modern technologies and facilities. Efforts to preserve the style and meaning of this house style should be doubled; this can be achieved through awareness in printed materials as well as digital format. Hence the need to study the traditional Malay spa design as it depicts one of the most appropriate traditional Malay architectural elements. It applies materials that are sustainable. This spa design embraces the environment in a relationship that respects each other. In order to understand the tropical Malay spa design, it is vital to understand the definition of spas and how they come about. The rising demand for spas is related to the changing lifestyle that requires a person to relax, reflect, revitalise and rejoice oneself. Segerberg, an international spa professional, elaborates that spa guests have the opportunity to take time to listen to their souls and bodies [2].

\section{Definition of spa}

According to the International SPA Association, spas are entities devoted to enhancing overall well-being through a variety of professional services that encourage the renewal of mind, body and spirit. The Bali Spa \& Wellness Association defines a similar interpretation, although with more focus on the Asian way [3]. On the other hand, Chamber's Encyclopaedic English Dictionary defines spa as a mineral water spring and a town in Belgium called Spa where such a spring was once located [4]. Spa is defined as a treatment of health to ensure total relaxation to those who receive the treatment. It can be categorised into six themes. They are [5]:

1. a resort providing therapeutic baths;

2. a resort area having mineral springs;

3. a fashionable hotel or resort;

4. a health spa;

5. a tub for relaxation or invigoration, usually including a device for rising whirlpools in the water.

Clark indicates that spas come in four types. They are the retreat spa, the resort spa, the day spa and the salon or mini spa [6]. They are all 
interchangeable, depending most importantly on the purpose of the spa and its location. Callen claims that the spa is no longer associated with mineral springs and therapeutic taking-of-the-waters. Spa currently comes in the form of chic pampering products that line the shelves of the plushest beauty boutiques and most desirable department stores, delicious and health boosting foods or the ultimate get away holiday destinations [7]. On the other hand, the oriental treatment of the Thai spa experience offers not just stress relief pampering but also delicious foods in exotic locations. The advantage of the Thai spa reveals that it combines traditional treatment, especially Thai massage, with a modern setting [8]. The Malay spa falls under the health category where the treatment is focussed on improving the health of spa users. This spa offers traditional beauty and health therapies aimed at enhancing well-being. It incorporates more modern therapies but is based on traditional rituals and customs. Their main focus is the body and soul, and achieving balance in one's life. Historically, the Malay spa treatment began by giving treatment mainly for women who were having problems with their health as well as post-natal treatment for new mothers [9]. Malay spa treatment for men was unheard of and never practised. This scenario was changed when the Thai spa and the Bali spa became popular in Malaysia. This paper also looks into the research objectives and the spa process requirements to be able to understand the spa design.

\section{Objectives and methodology}

The objectives of this research are mainly to stress the importance of recording the remaining Malay spa design in the two states of the Peninsular Malaysia, namely Kedah and Terengganu. Most of the recording and collection information for the database are produced in hard copies and digital format. The objectives are as follows:

1. to identify the interior space planning of the Malay spa design for their functions;

2. to explore the philosophy that is related to the interior space planning, the surrounding environment as well as the functions;

3. to examine the cultural influences on the interior space planning and the functions of the details embellishment and the philosophy associated with them.

The methodology employed for this explorative research gears towards content analysis and the understanding of Malay spa practices and spa design. It relies heavily on the availability of a literature review of very limited references. Most of the references pointed to the other type of spas, namely the Thai spa and the Bali spa. These also include largely references on traditional Chinese treatment through reflexology and tai chi kung and Indian ayurvedic treatment via traditional spices and herbal treatment. They can be found in a lot of old texts, scriptures and book of rituals. However, references on the Malay spa are unheard of if not too few and difficult to access. Thus, most of the information on the Malay spa relies heavily on first hand information acquired through 
interviews with spa owners and spa practitioners. Interviews with midwives who are still practising traditional medicine that are embellished with rituals will shed some information on the traditional Malay spa practice. These activities are done simultaneously with visits to known traditional Malay spas, such as at the Tanjong Jara, Terengganu and at the Ishan and Embun spas in Langkawi, Kedah. The rarity of the traditional Malay spas poses some challenge in the data collection process. Visual data collection activity that is done at the same time as the visits to the spas will give a clear picture on the operational process of Malay spas. The spas at the identified locations are also the case studies for this research, highlighting the meaning of the Malay spa in a proper rustic and traditional Malay village setting. Simultaneously, the documentation of the spa design takes place in the form of space analysis and the environment of the house.

\section{Malay spa philosophy and rituals}

According to Saad, a Malay spa practitioner, the Malay spa is not popular among Malaysians because the treatment is a well kept secret [10]. One of the excuses that contribute to the Malay spa being less known is that the Malay people do not want non-Malay people to know about the spa treatment. Only the Malay people have the privilege to inherit and learn about this traditional practice. Cultural values play important roles in keeping this tradition, which is passed down via oral traditions that embrace customs, rituals and taboos [11]. Another fear is that the Malays are very protective of their culture and this is what has kept the Malay spa alive, albeit less known. Moreover, the fear of this secret falling into the wrong hands is so strong and almost over protects the knowledge. Another reason is that the Malay spa practitioners feel that most of the treatment and rituals in Malay spas involve the reciting of the Koranic verses. This is another issue that prevents non-Muslims from using Malay spas. However, according to a few Islamic teachers, the Koranic verses that are uttered during the rituals are combined with animistic belief chants, thus making the spa practice non-Islamic. Nevertheless, the culture is still Malay and the Malay spa is only known to the Malays, but the need to expose and promote its uniqueness has become apparent. This traditional treatment deserves a better acknowledgement and appreciation for it promotes a healthy life style as well as awareness of one's' well being. Since the increase of demand for alternative health treatment, the Malay spa has been making a comeback, although at a very slow pace. The herbal treatment of the Malay spa consists of kaffir lime, pandanus leaf, cinnamon stick, black cumin, clove and many types of roots of trees. They are used for treatments with the belief that these herbs and plant parts carry some medicinal properties that would be able to heal, rejuvenate and cure the recipients of these treatments from ailments. Flowers are also used in spa treatments. The flower ingredients come from seven varieties of flower namely rose (mawar - rosa spp), bullet wood (bunga tanjung - mimosops elengi), tropical gardenia (bunga china - gardenia augusta), tropical magnolia (bunga cempaka - michelia champaca), frangipani 
(bunga kemboja - plumeria acuminata), ylang ylang (bunga kenanga canagium orodatum)) and jasmine (bunga melur - jasminum sambac) [12].

The advantages of having a Malay spa treatment include the offering of a total health treatment where a person is treated with a proper diet to detoxify the inner body and a herbal treatment to cleanse the outer parts [13]. The pampering treatment includes a floral bath, sand heat treatment, foot bath treatment and face and hair treatment. It is known as treatment from hair to toes. All of these treatments are undertaken with specific rituals according to the requirements of the treatment. They are usually accompanied by the usage of seven types of flowers and water, as the fragrant smells of the flowers and water cleanse the physical and the spiritual entities, thus bringing good health to the spa users. The rituals are heavily embedded with traditional philosophies depicting the strong beliefs of the Malay people of supernatural powers. The Malay people, namely the rural folks, are well associated with the traditions and customs of the Malay traditional lifestyles. Every single type of behaviour calls for a proper custom that is well embedded with superstitious beliefs. These beliefs were passed on through generations via oral traditions and they have become necessary in undertaking any ritual that mainly concerns the health and well-being of a person. Osman describes that the most pervasive influence that folk beliefs have on an individual villager is in matters of health. The village practitioner in the art of curing may use herbs or even engage in bone-setting as the situation demands [14].

Although most of the medicine men practise the traditional medicine intertwined with the Islamic beliefs through the reciting of Koranic verses, the philosophy and the rituals are heavily laced with the animist and Hindu-Buddhist beliefs. The people are the same but the religious beliefs change through time to accommodate the coming of new beliefs, hence the move from the animist to Hindu-Buddhism and finally Islam [15]. However, the philosophy and the rituals remain the same but the chanting and the incantation to accompany the rituals are related to the religious beliefs at that time. Historically, the principle of mantra or incantation is basically magical. The intention is to influence the disposition of the supernatural and to make the healing process successful and beneficial to the so called sick person [16]. Specifically in the Malay spa treatment, the ritual of bathing that comes with incantations is related to Islamic beliefs and only certain herbs and flowers can be used to execute the ritual. Flowers must be fragrant and white or cream in colour [17]. All the rituals found in the Malay spa treatment take place in a secluded area within the compound of a house. As the Malay spa treatment is still considered a secret, most people will not be able to see the rituals being performed in a setting that is also known to be a hideout. Thus, the spa treatment also relies heavily on its setting and design, mainly within a traditional Malay house vicinity.

\section{Tropical Malay spa design and setting}

Although spa design can be interpreted in many ways according to the culture's specific requirements, the Malay spa design is confined to the tropical design 
parameters. The Malay spa started as a treatment mainly for women and was done in their own back yards. The tropical surrounding that contains a village provides a natural setting where the sources for the spa treatment are readily available (figure 2). These environs feature the planting of many types of herbal plants, flowers, spices and fruit trees.

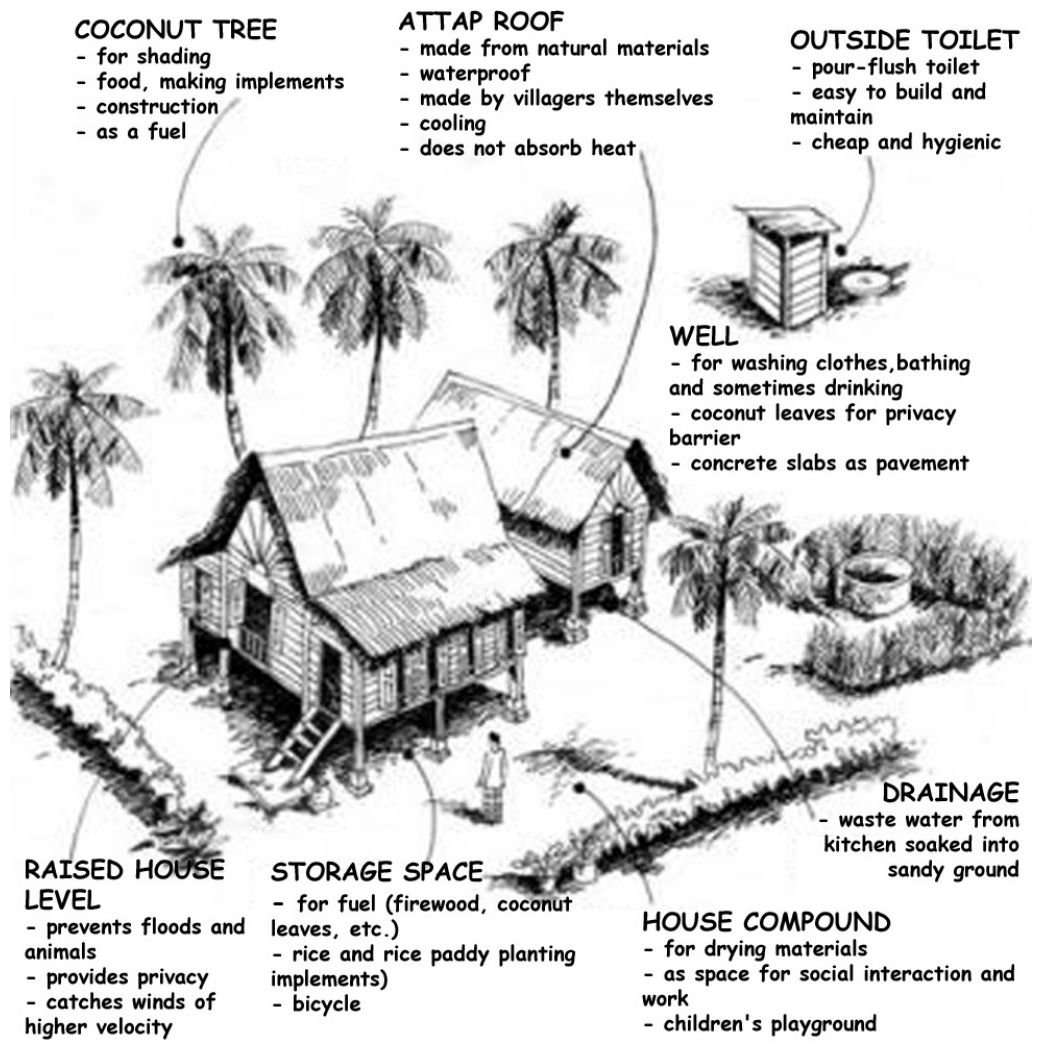

Figure 2: The environs of the house.
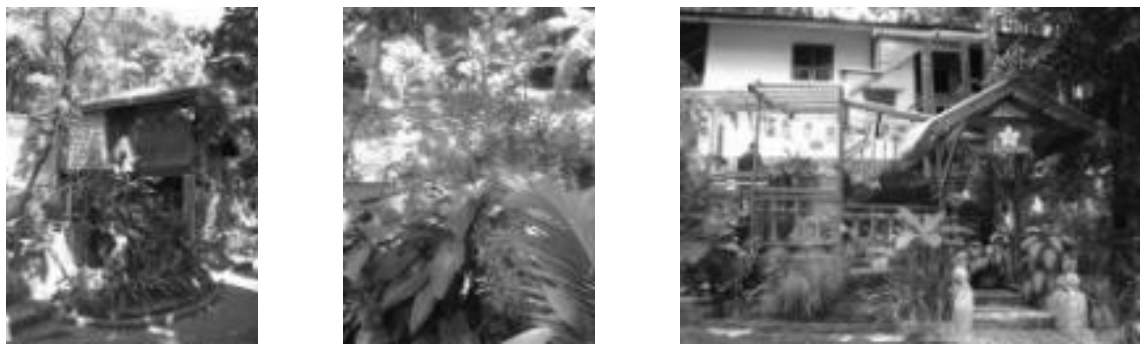

Figure 3: The area. Figure 4: Spice garden.

Figure 5: Fruit trees. 
All the ingredients needed are accessible within a few metres from where the treatment usually takes place (figures 3 and 4). Malay house is a place that provides security sheltering the inhabitants from the weather elements and also features some artistic impressions through the traditional carvings and decorative architectural components (figure 5) [18]. However, all these elements are based on spiritual beliefs that influence the surroundings as well as the house. The design of a Malay spa design has an influence on its surroundings. Associated with the traditional Malay house called the Single's House (rumah bujang,), its spa architecture is a three dimensional art where it combines art and functional space for the interior as well as the exterior.

A Malay spa design is built on the beliefs that every element in the house has spiritual powers that protect the owners. The surrounding is closely related to the house thus making it important to place the house in a right setting. Appropriately, according to Lim, the compound of a Malay house is planted with vegetables and fruit trees that in return create a boundary, a well shaded compound that provides privacy as well as a place to work [19]. The privacy gained from the setting of the house offers a place for spa treatment as the ingredients for the ritual are within reach and sheltered from the prying eyes. However, the Malay house within itself has different zones or domain. These domains will determine where the ritual of the traditional Malay spa will take place. Historically, as the spa treatment was only meant for women, the setting for the rituals would only be performed in the female domain namely at the back of the house using fruit trees or shrubberies as fencing for privacy. A Malay house design is divided into two main domains (figure 6). The front portion of the house is the male domain where young women are kept away while the back portion of the house is the female domain (figure 7). It is a clear indication of the relationship between male and female and reflecting formal social interactions [20]. The male domain features of more open spaces especially the veranda where interactions among males take place publicly (figure 8). The female domain is reserved for activities that are sited only in the kitchen and the side veranda (figure 9). The Malay spa is often located at the back of the house, in the side veranda area and sometimes in the dining area that is connected to the kitchen (figure 10).

This illustrates that the Malay spa is a very personal activity for it relates to the ritual of healing a sick person as well as keeping it secret from prying eyes. Since the kitchen is always close to the well, a source of water, and to the herbal

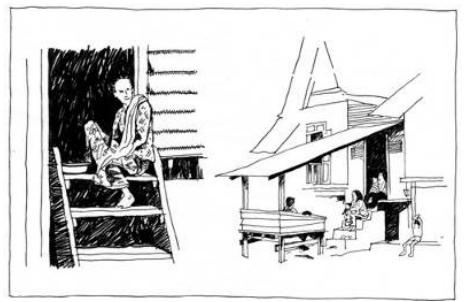

Figure 6: Domains of genders.

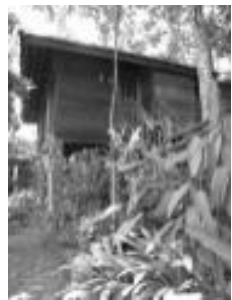

Figure 7: Kitchen. Figure 8: Veranda.

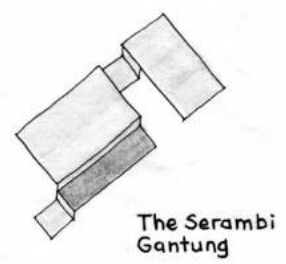

The Seram
Gantung 
plants, flowers and spice planting beds, the female domain seems the most appropriate place for the Malay spa. Malay cultural and social structures have moulded all activities according to gender. Historically, the Malay spa is far from the indulgence activities people are seeing today. It is a necessary process for healing the sick people (figure 11).The internal environment of the traditional Malay spa design designates all activities relating to private requirements to the back of the house (figure 12). Nasir indicates that a house symbolises a human body that consists of many parts [21]. Thus every part of the house has to be properly designed according to its function. Since the activities involved in the Malay spa are of a healing nature, the interior of the house is designed to cater for the activity's requirements. At times, this is also a place for the family to wash a corpse of a relative before burial. Thus the design of the floor is equipped with drilled holes in the wooden planks (figure 13) [22].

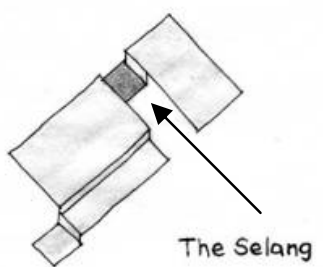

Figure 9: Passageway.

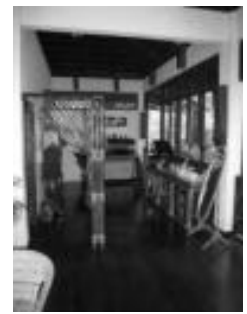

Figure 10: Passageway.

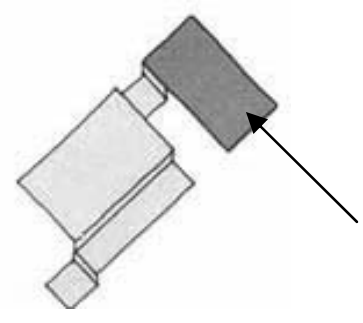

Figure 11: Kitchen.

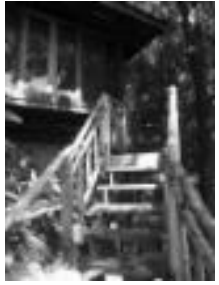

Figure 12: Kitchen.

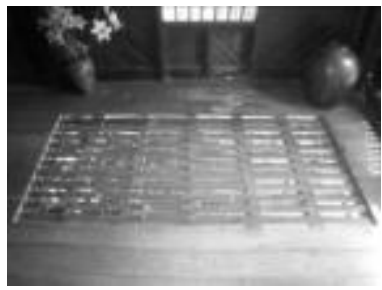

Figure 13: Holes in floor. Figure 14: Bamboo floor.

\subsection{Construction solutions and environmental benefits}

The Malay spa design in its association with the Single's House applies a simple construction method using local materials. Timber is the main material that made up the main frame of the house. Bamboo is used as the floor material (figure 14) that provides gaps in between bamboo pieces to allow dust to fall onto the ground as well as to drain water to the ground. Materials that are used for the construction of the spa design have always been from the sources that are renewable or farmable found in the Single's House (figure 15). They contribute to the low impact on the environment as compared to the current modern materials. Furthermore, the materials are accessible and require minimal efforts to acquire them. A process that takes place in a Malay spa treatment always involves the usage of water for cleansing and herbs for healing. All of these 
requirements have a proper place in the kitchen or in the closed side veranda. The spaces are designed with the activities in mind before the construction of the Malay house. This is a clear indication that the Malay spa is holistic. It requires the interaction between the social and cultural values of the Malay people. It is a part of the Malay life style and is kept secret because it is known to have involved the sacred sanctity and the ritual of the society.

Internally, the house designed is not just for personal use to shelter families but also a place for communal activities, a gathering space for comfort and peace. The breakdown of the interior space planning iterates the various functional spaces. However, all of these spaces function with no definite boundaries. Only the activities can determine the use of the spaces (i.e. cooking - kitchen, communal activities - main area). The invisible borders create an openness of the interior of the house thus making the internal part seems big and airy. Since there is no ceiling constructed, the roof structure is left open directly to the underside of the roof. Spacious interior is created with almost a double volume due to the open roof configuration. This situation in the interior design of the spa design house provides a cool interior in tropical climes that is governed by sun heat, radiation, rain, wind and humidity. The components of the Malay spa go further with not only providing the basic shape and construction of a house but also displaying a lot of embellishments that function just as important as the main structure of the house.

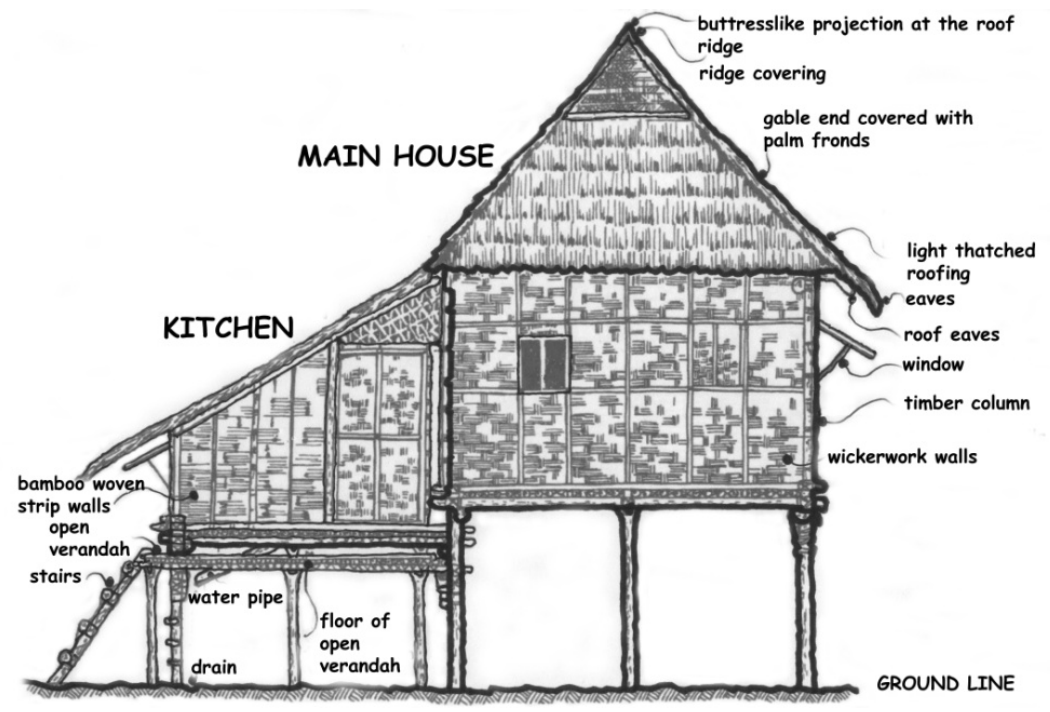

Figure 15: Construction materials of the single's house.

\section{Conclusions}

This paper has discovered that the tropical Malay spa design in the Single's House and its practices have long been established. The architecture and the 
culture associated with the spa practices indicate a sustainable scenario whereby the architecture that houses the sustainable culture is also sustainable. As the traditional Malay house is always constructed according to the surroundings, the practice of the Malay spa associated with the Malay house reveals of its spiritual elements. The house itself is embellished with cultural beliefs thus strengthening the customs and rituals practices attached to the Malay spa. In whole, the spa design housed in a traditional Malay Single's House embodies the true Malay traditions as every parts of the house and its activities are rich with philosophy and traditional beliefs. It is also known that the efforts to make the Malay spa exclusive only for the Malay people have hindered its promotion and exposure for the fear that the spa knowledge would fall into the wrong hands. On the other hand, the architectural elements portrayed are made strong with the cultural elements of customs and rituals and the natural surroundings thus signifying a symbiotic relationship. It pays respect to nature and its surrounding elements. The traditional Malay spa design though humble in its appearance has shown a house construction that is intelligent and smart in responding to nature and its surroundings. The analysis on the facts of the Malay spa design that incorporated traditional cultural issues such as philosophy, traditions, rituals and customs have resulted in the outcomes as follows:

- A comprehension of interior space planning in a traditional Malay house according to functions.

- A thorough understanding on spaces in relation to cultural requirements.

- An understanding on the interior space layout in relation to sustainable home design

- A deeper understanding of the traditional construction of a traditional Malay house according to rituals, customs and traditions.

- An understanding of the requirements of this house design for construction in specific environments and climates.

This paper has shown that the heritage and culture that is visible has been passed on through generations. However, the culture is dying out due to the modernisation and new technology in building construction. The lack of interest in this type of architecture especially among the young generations ensures the demise of the knowledge. The Malay spa design has outlined all the rules about designing in and with nature. It has also shown that mankind can coexist with nature that perpetuates their existence. The Malays spa design is the embodiment of the Malay culture starting from its uncomplicated beginning. It features knowledge that tells stories of by gone eras through its construction, embellishments, interior space planning, materials, form and shape. Most important of all, the traditional Malay spa design has put forward an identity that is intelligent in design and in combining traditional customs, rituals and philosophies in every element of the form. It is a house that displays design sustainability with aspects of economy, social and environmental as the prime factors that at the end creates its character and identity in cause that is full of history and cultural elements. 


\section{References}

[1] Hanafi, Z. (1996). Pembinaan Bangunan Tradisional Melayu. Kulim: Amber-Solara.

[2] Clark, A. J. (2005). Australia's Best Spa - The Ultimate Guide to Luxury and Relaxation. Singapore: Periplus.

[3] The Bali Spa \& Wellness Association (BSWA). http://balispawellnessassociation.org/.

[4] Robert Allen (ed.). (1994). Chambers Encyclopedic English Dictionary. Edinburgh: Chambers.

[5] Spa. http://www.thefreedictionary.com/spa

[6] Chan, B. (2006). Asia’s Luxury Spas. Singapore: Page One.

[7] Callen, K. (2001). Spa - Pamper Body and Soul. London: Ebury Press.

[8] Jotisalikorn, C. (2002). Thai Spa Book - The Natural Asian Way to Health and Beauty. Singapore: Periplus.

[9] Hasan, Z., Mazlan, N.A. \& Yaacob, M. (2005). Tumbuhan Ubatan untuk Kesejahteraan Wanita. Kuala Lumpur: MARDI.

[10] Daud, H. (1989). Sejarah Melayu: Satu Kajian Daripada Aspek Pensejarahan Budaya. Kuala Lumpur: Dewan Bahasa dan Pustaka.

[11] Deraman, A.A. (1994). Masyarakat dan Kebudayaan Malaysia. ed. 2. Kuala Lumpur: Cahaya Pantai.

[12] Bahauddin, A. (1999). Contemporary Malaysian Art - An Exploration of the Songket Motifs. Unpublished PhD Thesis. Sheffield: Sheffield Hallam University.

[13] Hasan, Z., Mazlan, N.A. \& Yaacob, M. (2005). Tumbuhan Ubatan untuk Kesejahteraan Wanita. Kuala Lumpur: MARDI.

[14] Osman, M.T. (1989). Malay Folk Beliefs - An Integration of Disparate Elements. Kuala Lumpur: Dewan Bahasa \& Pustaka.

[15] Kasimin, A. (1991). Religion and Change among the Indigenous People of the Malay Peninsula. Kuala Lumpur: DBP.

[16] Osman, M.T. (1989). Malay Folk Beliefs - An Integration of Disparate Elements. Kuala Lumpur: Dewan Bahasa \& Pustaka.

[17] Yaacob, M., Maarof, M.G. \& Puteh, M. (eds.). (2005). Penanaman Tumbuhan Ubatan \& Beraroma. Kuala Lumpur: MARDI.

[18] Mat Jusin, Z. \& Irin, M.I. (eds.). (2000). The Traditional House Architecture of Malaysia. Melaka: PMCT.

[19] Lim, J. Y. (1987). The Malay House - Rediscovering Malaysia's Indigenous Shelter System. Penang: Institut Masyarakat.

[20] Chen, V.F. (ed.). (1998). The Encyclopaedia of Malaysia Architecture. Singapore: Archipelago Press.

[21] Nasir, A.H. \& Wan Teh, W.H. (2004). The Traditional Malay House. Kuala Lumpur: Fajar Bakti.

[22] Killmann, W., Sickinger, T. \& Hong, L. T. (1994). Restoring \& Reconstructing the Malay Timber House. Kuala Lumpur: FRIM.

Yahya, M.A. (1995). Simbolisme dalam Seni Bina Rumah Melayu. Kuala Lumpur: Dewan Bahasa \& Pustaka. 